1

2

\title{
The Impacts of Increased Heat Stress Events on Wheat Yield under Climate Change in China
}

\author{
Xuan Yang ${ }^{1,2}$, Zhan $\operatorname{Tian}^{3}$, Laixiang $\operatorname{Sun}^{4,5,6}$, Baode Chen ${ }^{2}$, Francesco N. Tubiello ${ }^{7}$, Yinlong Xu ${ }^{8}$
}

1. National Meteorological Centre of China Meteorological Administration, Beijing100081, China

2. Shanghai Typhoon Institute of China Meteorological Administration, Shanghai 200030, China

3. Shanghai Climate Center, Shanghai Meteorological Service, Shanghai 200030, China

4. Department of Geographical Sciences, University of Maryland, College Park, MD 20742, USA

5. International Institute for Applied Systems Analysis (IIASA), A-2361 Laxenburg, Austria

6. School of Finance \& Management, SOAS, University of London, London WC1H 0XG, UK

7. Statistics Division, Food and Agriculture Organization of the United Nations (FAO), Rome, Italy

8. Institute of Agro-Environment and Sustainable Development, Chinese Academy of Agricultural Sciences, Beijing, China

Correspondence to: Zhan Tian, E-mail: tianz@,1ries.ac.cn, Tel: +86-21-54896481, Fax: +86-21-54896465; or Laixiang Sun, Email: LSun123@umd.edu, Tel: +1-301-405-8131, Fax: +1-301-314-9299.

Acknowledgement: We thank one member of the editorial team and three reviewers for their criticism and very constructive revision suggestions. This work was supported by the National Natural Science Foundation of China (Grant Nos. 41371110, 41671113, 41601049 and 41401661), and the China's 12th Five-year National Science \& Technology Pillar Program (Grant No. 2013BAC09B04 and 2016YFC0502702). 
Version of the article accepted for publication in Climatic Change published by Springer online 12 Jan 2017. Published version available at: $\underline{h t t p: / / l i n k . s p r i n g e r . c o m / a r t i c l e / 10.1007 / s 10584-016-1866-z ~}$

Accepted version downloaded from SOAS Research Online: https://eprints.soas.ac.uk/23476/

\section{ABSTRACT}

China is the largest wheat producing country in the world. Wheat is one of the two major staple cereals consumed in the country and about $60 \%$ of Chinese population eats the grain daily. To safeguard the production of this important crop, about $85 \%$ of wheat areas in the country are under irrigation or high rainfall conditions. However, wheat production in the future will be challenged by the increasing occurrence and magnitude of adverse and extreme weather events. In this paper, we present an analysis that combines outputs from a wide range of General Circulation Models (GCMs) with observational data to produce more detailed projections of local climate suitable for assessing the impact of increasing heat stress events on wheat yield. We run the assessment at 36 representative sites in China using the crop growth model CSM-CropSim Wheat of DSSAT 4.5. The simulations based on historical data show that this model is suitable for quantifying yield damages caused by heat stress. In comparison with the observations of baseline 1996-2005, our simulations for the future indicate that by 2100 , the projected increases in heat stress would lead to an ensemble-mean yield reduction of $-7.1 \%$ (with a probability of $80 \%$ ) and $-17.5 \%$ (with a probability of $96 \%$ ) for winter wheat and spring wheat, respectively, under the irrigated condition. Although such losses can be fully compensated by $\mathrm{CO}_{2}$ fertilization effect as parameterized in DSSAT 4.5, a great caution is needed in interpreting this fertilization effect because existing crop dynamic models are unable to incorporate the effect of $\mathrm{CO}_{2}$ acclimation (the growth enhancing effect decreases over time) and other offsetting forces.

KEY WORDS: Extreme weather events; heat stress; probabilistic assessment; wheat yield; climate change, China. 
Version of the article accepted for publication in Climatic Change published by Springer online 12 Jan 2017. Published version available at: $\underline{h t t p: / / l i n k . s p r i n g e r . c o m / a r t i c l e / 10.1007 / s 10584-016-1866-z ~}$

Accepted version downloaded from SOAS Research Online: https://eprints.soas.ac.uk/23476/

\section{INTRODUCTION}

China is the largest wheat producing country in the world, with a share of $11 \%$ in global wheat areas and $17 \%$ in global wheat production during the 2014-2015 marketing year (USDA, 2016). Wheat is the staple food grain in north China and is eaten in the form of steamed bread and noodles. Chinese government and famers have worked very hard to maintain record or near-record levels of wheat production at about 130 million tons in recent years. However, strong domestic demand for premium quality wheat has continued to result in significant wheat imports at a scale of 2 to 6.8 million tons per year during 2011-2015 (FAO- GIEWS, 2016; USDA, 2016). China's effort to maintain basic self-sufficiency in wheat supply in the future will further face the challenge posed by global warming and the resultant increase in the occurrence and magnitude of adverse and extreme weather events, including heat stress. An improved understanding of this new challenge will be of great importance not only for food security in the country but also for the stability and sustainability of the world's food market.

There is a growing body of literature that employs various crop-growing models to simulate the impact of increasing temperature during the growing season on crop production (e.g., Lobell \& Asner 2003; You et al. 2009; Asseng et al. 2011, 2015; Liu and Tao 2013; Tao and Zhang 2013; Deryng et al. 2014). However, these studies mostly considered the impact of growing season mean temperature on crop development and yield. Teixeira et al. (2013) construct a daily yield damage intensity factor within a 30-day period centered on flowering to estimate the potential yield damage caused by high daily temperatures. Their damage intensity factor ranges from 0 when daytime temperatures (not maximum) are less than or equal to a crop specific critical temperature and increased linearly to a maximum value of 1 when day temperature reached a limiting upper threshold. The method is attractive in its simplicity, but it cannot account for processes of crop growth and development. In this research we assess the impact of high daily temperatures on wheat growth and development at thirty-six representative observation stations in China (cf. Table S1) and to quantify yield damage caused by heat stress events.

The crop growing model employed in this study is the CropSim module in the cropping 
Version of the article accepted for publication in Climatic Change published by Springer online 12 Jan 2017. Published version available at: http://link.springer.com/article/10.1007/s10584-016-1866-z

Accepted version downloaded from SOAS Research Online: https://eprints.soas.ac.uk/23476/

system model (CSM) of the Decision Support System for Agro-technology Transfer (DSSAT) (Jones et al. 2003; Hoogenboom et al. 2010). DSSAT is process-oriented and dynamic. It has been widely used for simulating the collective effects of crop genetics, management practices, and weather and soil conditions on the growth, development, and yield of individual crops for more than 25 different crops in various countries around the world, ${ }^{1}$ and recently for assessing the impact of rising seasonal mean temperatures on wheat yield (Asseng et al. 2015). The CSM-CropSim has a multiplying algorithm to represent crop's initial response to elevated $\mathrm{CO}_{2}$, but the algorithm is unable to parameterize the process of $\mathrm{CO}_{2}$ acclimation, i.e., the growth enhancing effect of elevated $\mathrm{CO}_{2}$ decreases over time (Long et al. 2004; Smith and Dukes 2013). We activate this algorithm in our simulations for taking into account the potential $\mathrm{CO}_{2}$ fertilization effect but with cautions in interpreting the relevant results.

To quantify yield damage caused by heat stress events, a challenging issue is how best to combine outputs from a wide range of GCMs with observational data, so as to produce robust future climate data in daily-step for crop impact assessment. Because the current GCMs are incapable of properly simulating daily variation of atmosphere owing to their coarse resolutions, which means that the drivers of local climate variation are not captured (Maurer and Hidalgo 2008), and more importantly, poor representation (e.g., parameterization) of physics, the daily weather output of GCMs should not be used directly as input into the CSM-CropSim simulation model. It was reported that certain distortions in daily weather variability can seriously bias crop model simulations (Semenov and Porter 1995; Baron et al. 2005). To address this issue, we employ a pseudo-global warming (PGW) method, in which the climate perturbation (or global warming signal) fields produced by GCMs are superimposed onto observed historical daily weather series at specific locations. With the PGW method, we can obtain a new daily data set that includes the future climate change signals produced from monthly mean data of GCMs' projection, which is widely regarded as being the most reliable so far; and the characteristics of daily weather events under the present-day climate, which is most likely to be preserved in the future. The PGW approach is

\footnotetext{
${ }^{1}$ For an informative review, see Timsina and Humphreys (2006).
} 
Version of the article accepted for publication in Climatic Change published by Springer online 12 Jan 2017. Published version available at: http://link.springer.com/article/10.1007/s10584-016-1866-z

Accepted version downloaded from SOAS Research Online: https://eprints.soas.ac.uk/23476/

based on the procedures developed in Schär et al. (1996) and has been adopted in many climate model downscaling studies and applications (Tubiello et al. 2000; Kawase et al. 2009; Rasmussen et al. 2011; Yoshikane et al. 2012; Lauer et al. 2013).

In the simulations, we work with 96 climate change scenarios, which are produced by applying the PGW procedure to 30 GCMs under 4 Representative Concentration Pathway (RCP) scenarios in the CMIP5 (Phase 5 of Coupled Model Inter-comparison Project) of the IPCC Fifth Assessment Report (cf. Table S2). Wheat growth simulations of the CSM-CropSim Wheat model under these 96 scenarios produce $960(96 \times 10$ years $)$ yield estimations at each station in each focal period. This in turn leads to 960 yield-loss/gain (yield in each scenario minus yield in the baseline) results at each station in each focal period. We use the frequency distribution of these 960 yield-loss/gain results to proxy the probability distribution of yield changes. This naturally leads to a probabilistic assessment of the impact of heat stress events. This probabilistic assessment method is potentially applicable for other crops and in other jurisdictions.

\section{MATERIALS AND METHODS}

\subsection{Study Sites}

Both winter wheat and spring wheat grow in China, typically in rotation with other crops such as maize and rice. Winter wheat accounts for about 95\% of China's total wheat output, with more than $75 \%$ of the crop produced in 5 provinces located on the North China Plain, which are Henan, Shandong, Hebei, Anhui, and Jiangsu, in the descending order of output share (FAO- GIEWS, 2016; USDA, 2016). A USDA's estimation indicates that about $85 \%$ of wheat areas is under irrigation or high rain-fall conditions (USDA, 2006) and therefore our presentation mainly focuses on the results under the irrigated condition.

We selected 36 agro-meteorological observation stations based on the following criterions. They (1) represent the typical cropping system for wheat cultivation in China; (2) differ in terms of geographic and climatologic characteristics; and (3) have over 10 years of records of wheat crop management information and weather data (including planting, anthesis and harvest dates, crop yield, as well as daily records of minimum and maximum temperature, 
Version of the article accepted for publication in Climatic Change published by Springer online 12 Jan 2017. Published version available at: $\underline{h t t p: / / l i n k . s p r i n g e r . c o m / a r t i c l e / 10.1007 / s 10584-016-1866-z ~}$

Accepted version downloaded from SOAS Research Online: https://eprints.soas.ac.uk/23476/

precipitation, and solar radiation). Of these 36 stations, 26 are winter wheat stations and 10 are spring wheat stations. General information on the location, climate and wheat cropping calendar at each of these stations is shown in Table S1. The order of stations in all tables and figures of this paper follows the order of planting dates (from the earliest to the latest).

\subsection{CSM-CropSim Wheat Model}

Crop simulation models are designed to assess the impacts of multiple climate factors on crop growth in a way considering how these factors interact with crop growth and yield formation processes that are sensitive to climate. Therefore they are widely employed in climate impact studies in the cropping sector (Challinor et al. 2014; Xiong et al. 2010; Ju et al. 2013). We employ the CSM-CropSim Wheat model of the DSSAT V4.5 to assess the impact of climate change and climate variability on wheat development and growth. Similar to other process-oriented crop dynamic models, the CSM-CropSim Wheat calculates daily phenological development (i.e., vegetative growth, flowering, grain growth, maturity and senescence phases) and biomass growth in response to environmental (soil and climate) and management (crop variety, planting conditions, $\mathrm{N}$ fertilization, and irrigation) factors. This model is routinely used for quantifying wheat yields under current conditions as well as under climate change scenarios across a wide range of environments in different countries (e.g., Challinor et al. 2005; Palosuo et al. 2011), including China (e.g., Xiong et al. 2008, 2010).

The overall temperature response of the CSM-CropSim wheat model is determined by the integration of a number of individual responses in the wheat growth cycle. Hunt and White (2013) present a technical overview of temperature response settings in the model. Its input files with information on crop management have a section dealing with environmental modifications. This setting allows a user to set up a sequence of simulation runs with the same general management, but with different conditions, for instance different sets of daily maximum and/or minimum air temperatures. Asseng et al. (2015) systematically test 30 different wheat crop models of the Agricultural Model Inter-comparison and Improvement Project (AGMIP) against field experiments. The tests are for growing season mean temperatures, which ranged from $15^{\circ} \mathrm{C}$ to $32^{\circ} \mathrm{C}$, including experiments with artificial heating. 
Version of the article accepted for publication in Climatic Change published by Springer online 12 Jan 2017. Published

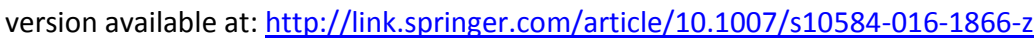

Accepted version downloaded from SOAS Research Online: https://eprints.soas.ac.uk/23476/

Their results show that the CSM-CropSim wheat model outperformed other models in terms of simulating anthesis and maturity dates, with an average performance in terms of simulating yield.

Elevated $\mathrm{CO}_{2}$ atmospheric concentrations decrease rates of photorespiration and initially enhance rates of photosynthesis and growth by a significant margin for $\mathrm{C} 3$ crops. This effect is represented by a simple multiplying algorithm with regard to the net assimilation rate. The

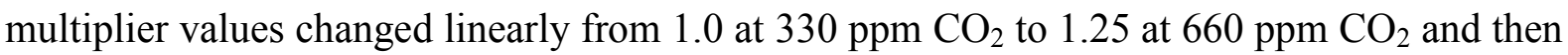
to 1.43 at 990 ppm $\mathrm{CO}_{2}$ (Hoogenboom et al. 2010). However, now we know that the above initial enhancement effect diminishes over time, a phenomenon known as $\mathrm{CO}_{2}$ acclimation (Long et al. 2004; Bloom et al. 2010), or can be eliminated by joint water and nitrogen limitation (Reich et al. 2014). ${ }^{2}$ The simple multiplying algorithm in CSM-CropSim is unable to capture the effect of this acclimation process and therefore, we must be cautious in interpreting the simulation results on the effect of $\mathrm{CO}_{2}$ fertilization.

\subsection{Cultivar Parameters}

The crop cultivar parameters, which are named genetic coefficients in DSSAT, quantitatively describe how a particular genotype responds to environmental factors. For example, field experiments reported in Fischer (1985) show a good correlation between kernel number and incident solar radiation in the 30 days preceding anthesis and a proportional relationship between the stem weight at anthesis and the grain number. The CSM-CropSim Wheat model approximates these relationships in mathematical constructs. However, because the exact quantification of the factors determining grain numbers are not well understood, the CSM-CropSim Wheat model needs to calibrate three cultivar coefficients based on field observations of crop growth process to compute grain numbers per

\footnotetext{
${ }^{2}$ Some other forces may also bring in eliminating effects. For example, rising levels of atmospheric $\mathrm{CO}_{2}$ is highly likely to increase the severity of wheat diseases, thus reducing yields (Váry et al. 2015); and disease levels can become worse when the plants and pathogens have been acclimatized to the higher concentrations of $\mathrm{CO}_{2}$ beforehand. Furthermore, weeds and other undesirable plants experience $\mathrm{CO}_{2}$ fertilization as well.
} 
Version of the article accepted for publication in Climatic Change published by Springer online 12 Jan 2017. Published version available at: $\underline{h t t p: / / l i n k . s p r i n g e r . c o m / a r t i c l e / 10.1007 / s 10584-016-1866-z ~}$

Accepted version downloaded from SOAS Research Online: https://eprints.soas.ac.uk/23476/

192

plant as determined by the cultivar's genetic potential, canopy weight, average rate of carbohydrate accumulation during flowering, and temperature, water and nitrogen stresses (Jones et al. 2003). These three cultivar coefficients are: G1 or the kernel number coefficient, presented as the number of seeds per unit canopy weight at anthesis (\#/g); G2 or the kernel weight coefficient, presented as normal seed weight under optimum conditions (mg); and G3 or the spike number coefficient, presented as the normal dry weight (total, including grain) of one unstressed stem at maturity (g). Such coefficient calibration makes the application of the model cultivar- and location-specific, and consequently, the sensitivity results are also cultivar- and location-specific.

Calibration of cultivar parameters itself is a knowledge- and technical-demanding work and our calibration for each of the thirty-six stations, which is based on the DSSAT-provided Generalized Likelihood Uncertainty Estimation method, has been published in Tian et al. (2012).

\subsection{Incorporating Natural Adaptation of the Growing Cycle}

We incorporate the natural adaptation of the growing cycle under heat stress in two steps. Simulations in the first step do not alter the sowing dates of the baseline but allow the growing cycle after the sowing dates to follow the growing dynamics specified in the CSM-CropSim wheat model, which means a natural adaptation of the growing cycle to the new weather pattern. In the second step, we extend the natural adaptation simulations to include changes on sowing dates.

In the simulations, the irrigated condition means that when the effective water content in the $0-20 \mathrm{~cm}$ soil layer is below $80 \%$ of moisture retention capacity, automatic irrigation set in the model takes place. Other management measures are set at the optimal levels to avoid disturbances caused by variations in management measures.

\subsection{Dataset}

Our analysis of climate change and climate variability is based on the simulations and projections of 30 GCMs used in the CMIP5 for the IPCC Fifth Assessment Report (AR5). In 
Version of the article accepted for publication in Climatic Change published by Springer online 12 Jan 2017. Published

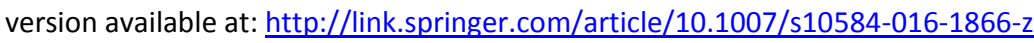

Accepted version downloaded from SOAS Research Online: https://eprints.soas.ac.uk/23476/

the CMIP5, radiative forcing scenarios are derived from representative concentration pathways (RCPs) (Moss et al. 2010; van Vuuren et al. 2011). Monthly minimum temperature, maximum temperature, precipitation, and solar radiation from historical runs and future scenarios are used and the climate data are obtained from 96 runs of projections for the early century (2016-2025), middle century (2046-2055), and the end of the century (2091-2100) under the RCP scenarios. Table S2 lists the GCMs used in this study, including model resolution, scenarios, and availability. A more detailed documentation of CMIP5 models can be found at http://cmip-pcmdi.llnl.gov/cmip5/.

Observed daily data (minimum and maximum temperatures, sunshine hours, precipitation) for the period of 1996-2005, which served as the baseline for the 36 stations, were provided by the Chinese Meteorological Data Center. Solar radiation was estimated using empirical global radiation models based on observed daily sunshine hours (Pohlert, 2004). Field data at the study sites, including anthesis and harvest dates, were also provided by the Chinese Meteorological Data Center (Table S1). Soil data were taken from Tian et al. (2012).

\subsection{PGW Approach}

In the PGW approach, the difference between present and future climate conditions simulated by GCMs was chosen to represent the climate warming signal or perturbation. To make the climate warming signal possess as little spatial variation (mostly from weather perturbations) as possible, the decadal climatology is used to average out the weather. The climate perturbation field (climate warming signal) is then added to the current weather field for the selected years, by linearly interpolating from monthly climatologies to each specified time period. In more detail, the climate warming perturbation field is obtained by subtracting the current (1996-2005) monthly 10-yr climatology from a future (2016-2025, 2046-2055, and 2091-2100, respectively) monthly 10-yr climatology, both from the same GCM projection. ${ }^{3}$ The climate perturbation field is then added to the current weather field. The

\footnotetext{
${ }^{3}$ For daily data, herein 10 year periods are considered sufficient to generate a climatology. Longer, 20 or 30 year periods should be used to obtain monthly climatologies.
} 
Version of the article accepted for publication in Climatic Change published by Springer online 12 Jan 2017. Published version available at: $\underline{h t t p: / / l i n k . s p r i n g e r . c o m / a r t i c l e / 10.1007 / s 10584-016-1866-z ~}$

Accepted version downloaded from SOAS Research Online: https://eprints.soas.ac.uk/23476/

difference between climatological fields used here to represent the climate warming signal must have as little spatial variation (mostly from weather perturbations) as possible, so the decadal climatology is used to average out the weather.

The signaling variables include minimum temperature, maximum temperature, precipitation, and solar radiation. The new daily data set is obtained by superposing the climate perturbation field to the observed daily data at each of the 36 stations. The superposing is done through linear interpolation from the monthly climatological predictions to each period in the observational daily data, with an assumption that monthly mean is valid on the $16^{\text {th }}$ of each month. The new daily data include the future climate change signals of the GCM perturbation while retaining the characteristics of daily weather events observed in the historical time-series. This was considered to be the most probable distribution in the future based on GCM information. This is because the climate perturbation's primary impact is on the large-scale planetary waves and associated thermodynamics, while the weather patterns entering the domain boundary remained structurally identical in both simulations in terms of frequency and intensity. Weather events can nonetheless evolve within the regional model domain due to altered planetary flow and thermodynamics (Rasmussen et al. 2011).

\subsection{Definition of Heat Stress in Thermal Sensitive Periods}

There is a large body of literature identifying the cardinal temperature thresholds for different phenological processes in wheat under experimental conditions. As summarized in the survey reports of Russell and Wilson (1994) and Porter and Gawith (1999), 31-32 ${ }^{\circ} \mathrm{C}$ are commonly regarded as the upper base temperature during the period immediately before anthesis. The official disaster grading standard of China Meteorological Administration (CMA-PAD, 2007) regards $32^{\circ} \mathrm{C}$ as the upper base temperature for defining heat stress events during the period prior to anthesis in China.

We double check the applicability of this official threshold by carrying out the following two sets of tests under the base-line climate. First, we test yield losses caused by imposing a single-day heat stress on the observed anthesis day for the consideration that short periods of heat stress during flowering period cause pollen indehiscence, disrupt pollination, decrease 
Version of the article accepted for publication in Climatic Change published by Springer online 12 Jan 2017. Published version available at: $\underline{h t t p: / / l i n k . s p r i n g e r . c o m / a r t i c l e / 10.1007 / s 10584-016-1866-z ~}$

Accepted version downloaded from SOAS Research Online: https://eprints.soas.ac.uk/23476/

the ability of pollen to germinate, and decrease the rate of pollen tube growth (Jagadish et al. 2010; Yadav et al. 2011). Second, we apply the above single-day heat stress event to a period from the $30^{\text {th }}$ day before anthesis to the $6^{\text {th }}$ day after anthesis so as to detect the most sensitive periods before and after anthesis. The results show that grain numbers are significantly reduced as a result of single-day heat in the period spanning from the $20^{\text {th }}$ day before anthesis to the anthesis day, when compared to the impacts prior to this 20-day interval. In contrast, the effect of single-day heat stress on each of the 6 days after anthesis is not significant. These two tests show that the period spanning from the $20^{\text {th }}$ day before anthesis to the anthesis day is the period most sensitive to heat stress featured by the maximum daily temperature exceeding $32^{\circ} \mathrm{C}$.

For the grain-filling period, the upper base temperature suggested in the literature is between 33.4 and $37.4^{\circ} \mathrm{C}$ (Russell and Wilson, 1994; Porter and Gawith, 1999). Therefore, it is not a surprise that yield reductions due to single-day heat-stress event above $32^{\circ} \mathrm{C}$ after anthesis is not significant in our tests. To identify the upper base temperature during the grain-filling period for popular cultivars in China, we test the impact of three consecutive days of heat-stress with maximum daily temperature exceeding $35^{\circ} \mathrm{C}$ during the grain-filling period. The results indicates that the yield reduction impact of such a heat stress event takes effect about one-week after anthesis, and imposing the same event on later days but before the end of the grain filling period will generate a similar level of damage.

Following the above findings, our thermal sensitivity assessments for the future climate conditions will focus on the following two periods: (a) The period spanning from the $20^{\text {th }}$ day before anthesis to the anthesis day, we name it the "pre-anthesis period", in which heat stress occurs if single-day maximum temperature exceeds $32^{\circ} \mathrm{C}$. (b) The period spanning from the $1^{\text {st }}$ to $20^{\text {th }}$ day after anthesis, we name it the "grain-filling period", in which heat stress occurs when maximum daily temperatures exceed $35^{\circ} \mathrm{C}$ on three consecutive days.

\section{RESULTS}

\subsection{Frequency and Intensity of Heat Stress Events}

Please note that we work with a set of climate change signaling variables, include 
Version of the article accepted for publication in Climatic Change published by Springer online 12 Jan 2017. Published version available at: $\underline{h t t p: / / l i n k . s p r i n g e r . c o m / a r t i c l e / 10.1007 / s 10584-016-1866-z ~}$

Accepted version downloaded from SOAS Research Online: https://eprints.soas.ac.uk/23476/

minimum temperature, maximum temperature, and precipitation, in the CSM-CropSim simulations. Because the ensemble-mean precipitation during the wheat growth season increases, by a moderate or significant scale at all study sites except Longhai, from the baseline of 1996-2005 to 2046-2055 and 2091-2100, and the decreases of precipitation in Longhai are less than $3.4 \%$, as shown in Table S3, our discussion in this paper mainly focuses on the impact of heat stress.

Table 1 reports the projected mean increases in the frequency of heat stress occurrence at each of the 36 study sites. It shows that the increases in the frequency of heat stress occurrence during both the pre-anthesis and grain-filling periods at the spring-wheat stations are much more significant than those at the winter-wheat stations. In the pre-anthesis period and compared with the baseline, the ensemble-mean frequency of heat stress occurrence is projected to increase by about 8 (probability: 54\%), 12 (70\%), and 18 (78\%) days/decade by 2016-2025, 2046-2055, and 2091-2100, respectively, at the winter-wheat stations. In contrast, the corresponding figures at the spring wheat sites are $30(60 \%), 41(85 \%)$, and $55(88 \%)$ days/decade. During the grain-filling period and in comparison with the baseline, the ensemble-mean frequency of heat stress occurrence increases by about $5(44 \%), 9(62 \%)$, and 15 (70\%) days/decade by 2016-2025, 2046-2055, and 2091-2100, respectively, at the winter-wheat stations; and by $22(58 \%), 31(76 \%)$, and $44(83 \%)$ days/decade at the spring-wheat sites.

To visualize the changes, Figures S2 and S3 depict the time series of the assembled maximum, mean, and minimum of the projected changes in monthly mean (Fig. S2) and maximum (Fig. S3) temperature from the baseline of 1996-2005, for each of the selected nine stations in the wheat production zone of northern China. All these time series show a rising trend. The assembled maximum shows the steepest rise in all stations, which implies (a) an increase in the intensity and (b) an increase in the variability of heat stress. Tables S4 and S5 summarize the assembled and decadal mean of the above-mentioned two changes from the baseline of 1996-2005 to each of the three periods: 2016-2025, 2046-2055, and 2091-2100, respectively. They show a trend of increase in both monthly mean and maximum temperatures at all study sites and the probability of such increase is between $92 \%$ and $100 \%$. 
Version of the article accepted for publication in Climatic Change published by Springer online 12 Jan 2017. Published version available at: $\underline{h t t p: / / l i n k . s p r i n g e r . c o m / a r t i c l e / 10.1007 / s 10584-016-1866-z ~}$

Accepted version downloaded from SOAS Research Online: https://eprints.soas.ac.uk/23476/

\section{(Tables 1, 2 and Figure 1 about here)}

\subsection{Ensemble Projections of Wheat Yield under the Irrigated Condition}

Table 2 reports the summary statistics of our simulations in terms of ensemble-mean yield changes, probability of yield change, and standard deviation of yield change relative to the baseline under the irrigated condition. Figure 1 presents the corresponding box plots. Table 2 and Figure 1 show that both the extent and probabilities of yield reduction increase with the GCM projected warming trend, at all 36 stations. To put this numerically, the ensemble-mean yield loss in comparison with the baseline will be 4.7 (with a probability of $71 \%), 5.4(75 \%)$ and $7.1(80 \%)$ percent by 2016-2025, 2046-2055, and 2091-2100, respectively. This suggests an increased risk of reduced yield in the middle and end of this century. In addition, the distributions of yield losses are increasingly skewed to the left when moving from 2016-2025 to 2091-2100, as evidenced by the co-increases of the standard deviation and the probability of yield loss in Table 2 and box plots in Figure 1. In contrast to distributions without severe skewness, this high and increasing left-skewness indicates that the increase in standard deviation does not necessarily imply increasing uncertainty in mean yield losses. This finding enriches the existing literature in the climate change impact assessment field.

Consistent with the higher sensitivity of spring wheat to heat stress (Tian et al., 2012) and stronger future warming at the spring wheat stations, the yield losses in spring wheat stations are generally more severe than their winter-wheat counterparts in terms of percentage reduction. Spring wheat yield is projected to decrease by 8.2 (with a probability of $93 \%$ ), 12.8 (96\%), and 17.5 (96\%) percent on average by 2016-2025, 2046-2055, 2091-2100, respectively.

There is an increasing body of literature assessing the impact of rising temperatures on wheat production. The most comprehensive one in this literature is Asseng et al. (2015), which systematically tests 30 wheat crop models against field experiments in 30 global locations, with warming signals imposed on growing season mean temperatures. In 
Version of the article accepted for publication in Climatic Change published by Springer online 12 Jan 2017. Published version available at: $\underline{h t t p: / / l i n k . s p r i n g e r . c o m / a r t i c l e / 10.1007 / s 10584-016-1866-z ~}$

Accepted version downloaded from SOAS Research Online: https://eprints.soas.ac.uk/23476/

comparison with their results at two winter wheat stations in China, ${ }^{4}$ our results of $7 \%$ yield reduction with a standard deviation of $9.6 \%$ by the end of the century are in line with the high end of the yield losses in their results under a $2{ }^{\circ} \mathrm{C}$ increase in seasonal mean temperatures and lower than their results with a $4^{\circ} \mathrm{C}$ increase in seasonal mean temperatures. In comparison with their results at the only spring wheat station, Harbin, which is located in far north of Northeast China, our results of $17.5 \%$ yield reduction with a standard deviation of $14 \%$ is in line with their results based on an imposed $4{ }^{\circ} \mathrm{C}$ increase in seasonal mean temperature.

\subsection{Natural Adaptation of Crop Growing Cycle}

We note that warming would allow for earlier planting of spring wheat and earlier ending of winter wheat dormancy, and this in turn would allow the crop to mature earlier, avoiding heat stress occurred later. Therefore, in our simulations, we allow for the natural adaptation of crop growing cycle to new climate patterns, meaning that the end of dormancy and mature dates will be determined endogenously by the model according to the growth dynamics of the cultivar under the new warming conditions.

In addition, we also run simulations on postponing the winter wheat plating dates within a window of 28 days and on bringing forward the spring wheat plating dates within a window of 28 days. The results for winter wheat do not show a statistically significant mitigation effect at virtually all winter wheat stations. The results for spring wheat at the two stations in Xingjian show that about $50-60 \%$ of the heat-stress induced yield losses can be avoided by this simple adaptation measure, but the results at other spring wheat stations do not produce statistically significant mitigation effect.

\subsection{Ensemble Projections of Wheat Yield under the Rain-fed Condition and Considering $\mathrm{CO}_{2}$ Fertilization Effect}

Although rain-fed wheat production accounts for less than $15 \%$ of total wheat production in China (USDA, 2006, 2016) and wheat growth at all 36 study sites are under irrigated

\footnotetext{
${ }^{4}$ They are Luancheng station in Hebei Province of North China Plain and Nanjing station in the lower reach of Yangtze River Basin.
} 
Version of the article accepted for publication in Climatic Change published by Springer online 12 Jan 2017. Published version available at: $\underline{h t t p: / / l i n k . s p r i n g e r . c o m / a r t i c l e / 10.1007 / s 10584-016-1866-z ~}$

Accepted version downloaded from SOAS Research Online: https://eprints.soas.ac.uk/23476/

condition, we run simulations at all stations under rain-fed conditions. Table S6 reports the summary statistics of this set of simulations and Figure S4 presents the corresponding box plots. They show that the ensemble-mean yield will increase, in comparison with the baseline, by $7.9,12.2$ and 15.4 percent for winter wheat and by $28.1,30.3$, and 30.5 percent for spring wheat in 2016-2025, 2046-2055, and 2091-2100, respectively. Such increases mainly result from the significant increase in precipitation during the wheat growing season. As reported in Table S3, in comparison with the baseline, the ensemble-mean increases in precipitation during the wheat growing season will be $18.9,31.6$, and 38.5 percent at the 26 winter wheat stations, and 50.1, 78.5, and 74.6 percent at the 10 spring wheat stations by 2016-2025, 2046-2055, and 2091-2100, respectively. However, even the highest yield-increase of 30.5\% cannot compete with the gain from irrigation, which typically stands at a level of $75 \%$ (USDA, 2006, 2016).

Tables S7 and S8 are the counterparts of Tables 2 and S6, respectively, when considering the $\mathrm{CO}_{2}$ fertilization effect. Figures S5 and S6 presents the corresponding box plots. Table S7 and Figure S5 indicate that with reference to the baseline, although the incorporation of $\mathrm{CO}_{2}$ fertilization effect under the irrigated condition cannot reverse the yield losses by 2016-2025, it will result in yield increases by 8.4 and 16.9 percent at winter wheat stations and by 3.4 and 9.3 percent at spring wheat stations by 2046-2055 and 2091-2100, respectively. Under the rain-fed condition, the effect of $\mathrm{CO}_{2}$ fertilization becomes more significant. The gain on the ensemble-mean yield will be 17.6, 42.5, and 70.2 percent for winter wheat and 39.6, 64.6, and 93.2 percent for spring wheat by 2016-2025, 2046-2055, and 2091-2100, respectively (Table S8 and Figure S6). This means that by the end of this century, the yield gain from the combined effect of increased rainfall and $\mathrm{CO}_{2}$ fertilization will have the potential to fully match the yield gain from irrigation and thus reduce irrigation water demand. However, as we discussed in Section 2.2, such yield gain could be illusive because the growth enhancing effect of $\mathrm{CO}_{2}$ decreases over time and the parameterization of DSSAT model is unable to incorporate such acclimation process.

\section{DISCUSSION AND CONCLUSION}


Version of the article accepted for publication in Climatic Change published by Springer online 12 Jan 2017. Published version available at: $\underline{h t t p: / / l i n k . s p r i n g e r . c o m / a r t i c l e / 10.1007 / s 10584-016-1866-z ~}$

Accepted version downloaded from SOAS Research Online: https://eprints.soas.ac.uk/23476/

Wheat is one of the two major staple cereals consumed in China and about $60 \%$ of Chinese population eats the grain daily. Basic self-sufficiency of wheat supply in the future will be of fundamental importance not only for food security in China but also for the sustainability of the world's food market. However future wheat production in China will face the challenge posed by the increasing occurrence and magnitude of adverse and extreme weather events such as heat stress. In this research we first combine outputs from a wide range of General Circulation Models (GCMs) with observational data to produce more detailed projections of local climate suitable for assessing the impact of increasing heat stress events on wheat yield. This is done by applying the Pseudo-global Warming Method (PGW) method to the outputs of 96 GCM-RCP combinations to effectively couple observed trend in historical weather fields with the difference components of the global warming signal produced by GCMs. These PGW-enhanced ensembles of climate change scenarios provide a robust way for ensuring a reliable probabilistic assessment of climate change impact on crop yield.

We then employ the CSM-CropSim Wheat model of DSSAT 4.5 to simulate wheat development and growth processes under current and future climate conditions at 36 representative observation stations in the major wheat growing areas of China. The simulations under current climate conditions indicate that the thermal sensitivity assessments should focus on two critical periods - one spanning from the $20^{\text {th }}$ day preceding flowering to the anthesis day, in which heat stress event occurs if single-day maximum temperature exceeds $32^{\circ} \mathrm{C}$; and the other spanning from the $1^{\text {st }}$ to the $20^{\text {th }}$ day after anthesis, in which heat stress events occur if maximum daily temperature exceeds $35^{\circ} \mathrm{C}$ on three consecutive days.

The ensemble of future climate conditions shows increasing frequency and intensity of heat stress incidence. The probability of such increase is also increasing with time. The CSM-CropSim simulations under the 96 climate change scenarios provide a probability assessment of future yield losses caused by heat stress events, which incorporate the natural adaptation of crop growing cycle to new climate conditions. Our discussion in this concluding section focuses on irrigated wheat production because it accounts for more than $85 \%$ of the total wheat production in China. The results show ensemble-mean yield 
Version of the article accepted for publication in Climatic Change published by Springer online 12 Jan 2017. Published version available at: $\underline{h t t p: / / l i n k . s p r i n g e r . c o m / a r t i c l e / 10.1007 / s 10584-016-1866-z ~}$

Accepted version downloaded from SOAS Research Online: https://eprints.soas.ac.uk/23476/

reductions at all 36 sites, with an increasing trend in terms of both yield reduction extent and the probability of yield reduction. In comparison with the baseline 1996-2005, the extent and probability of yield reduction by $2091-2100$ are $7.1 \%$ and $80 \%$, respectively, for winter wheat, and $17.5 \%$ and $96 \%$, respectively, for spring wheat. The results for winter-wheat are in line with the high end of the yield losses in Asseng et al. (2015) under a $2^{\circ} \mathrm{C}$ increase in seasonal mean temperatures at Luancheng and Nanjing stations. The results for spring wheat are in line with the results of Asseng et al. (2015) on an imposed $4^{\circ} \mathrm{C}$ increase in seasonal mean temperature at the Harbin station. Although the $\mathrm{CO}_{2}$ fertilization effect as parameterized in DSSAT 4.5 can compensate these losses, such fertilization effect might be illusive because the effect of $\mathrm{CO}_{2}$ acclimation (i.e., the growth enhancing effect decreases over time) and other offsetting forces are not considered in the parameterization of existing crop growth models (Smith and Dukes 2013).

Two limitations of this research are worth mentioning. First, despite the advantage of the PGW method in generating coherent and robust scenarios which preserve the characteristics of observed daily weather events while incorporating GCM-derived increases in frequency and intensity, it is unable to consider the nonlinear interaction between climate change and inter-annual variations in regional climate systems. The approach also implies the assumption that the same frequency and intensity of weather perturbations occur in the regional simulation domain for mean conditions of future climate (Rasmussen et al. 2011). These two weaknesses mean that the uncertainty caused by changes in inter annual variability is still not accounted for in the probability assessment of this research. Second, the simulation results from one crop model only are subject to the limitations on thermal-sensitivity in this crop model. As highlighted in Asseng et al. $(2013 ; 2015)$, a greater proportion of the uncertainty in climate change impact assessments can be attributed to variations across crop models. While the present study enriches the literature by assessing the impact of daily heat stress events under future climate change on wheat growth and development with the assistance of a highly dynamic crop model, future assessments will benefit from extended analyses using multiple crop models. 
Version of the article accepted for publication in Climatic Change published by Springer online 12 Jan 2017. Published version available at: $\underline{\text { http://link.springer.com/article/10.1007/s10584-016-1866-z }}$

Accepted version downloaded from SOAS Research Online: https://eprints.soas.ac.uk/23476/

477

478 
Version of the article accepted for publication in Climatic Change published by Springer online 12 Jan 2017. Published version available at: $\underline{h t t p: / / l i n k . s p r i n g e r . c o m / a r t i c l e / 10.1007 / s 10584-016-1866-z ~}$

Accepted version downloaded from SOAS Research Online: https://eprints.soas.ac.uk/23476/

479

480

481

482

483

484

\section{REFERENCES}

Asseng S, Foster IAN, Turner NC (2011) The impact of temperature variability on wheat yields. Global Change Biol 17:997-1012. DOI: 10.1111/j.1365-2486.2010.02262.x.

Asseng S, Ewert F, Rosenzweig C, et al. (2013) Uncertainty in simulating wheat yields under climate change. Nat Clim Change 3:827-832. DOI: 10.1038/NCLIMATE1916.

Asseng S, Ewert F, Martre P, et al. (2015) Rising temperatures reduce global wheat production. Nat Clim Change 5:143-147. DOI: 10.1038/NCLIMATE2470.

Baron C, Sultan B, Balme M, et al (2005) From GCM grid cell to agricultural plot: scale issues affecting modelling of climate impact. Philos T R Soc Lond B Biol Sci 360:2095-2108. DOI: $10.1098 /$ rstb.2005.1741.

Bloom A, Burger M, Asensio J R, Cousins A (2010) Carbon dioxide enrichment inhibits nitrate assimilation in wheat and Arabidopsis. Science 328: 899-901. DOI: 10.1126/science.11864.

Challinor A J, Wheeler T R, Craufurd P Q, Slingo J M (2005) Simulation of the impact of high temperature stress on annual crop yields. Agr Forest Meteorol 135:180-189. DOI: 10.1016/j.agrformet.2005.11.015.

Challinor A J, Watson J, Lobell D B, Howden S M, Smith D R, Chhetri N (2014) A meta-analysis of crop yield under climate change and adaptation. Nature Clim. Change 4:287-291. DOI: $10.1038 /$ nclimate2153.

CMA-PAD (China Meteorological Administration, Policy and Regulation Department) (2007) Disaster Grading Standard on Dry-hot Wind for Wheat. QX/T 82-2007. Beijing, China Meteorological Press, 547-555. (in Chinese).

Deryng D, Conway D, Ramankutty N, Price J, Warren R (2014) Global crop yield response to extreme heat stress under multiple climate change futures. Environ. Res. Lett. 9, 034011 (13pp). DOI: $10.1088 / 1748-9326 / 9 / 3 / 034011$.

FAO- GIEWS (2016) GIEWS Country Briefs: China, 22-March-2016. Available at: http://www.fao.org/giews/countrybrief/country.jsp?code=CHN.

Fischer RA (1985) Number of kernels in wheat crops and the influence of solar radiation and temperature. J Agr Sciences, 105, 447-462.

Hoogenboom G, Jones JW, Wilkens PW, et al. (2010) Decision Support System for Agro-technology 
Version of the article accepted for publication in Climatic Change published by Springer online 12 Jan 2017. Published

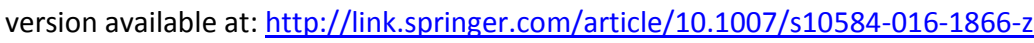

Accepted version downloaded from SOAS Research Online: https://eprints.soas.ac.uk/23476/

Transfer, Version 4.5, Volume 1: Overview. University of Hawaii, Honolulu, USA.

Hunt, LA and White JW (2013) The CSM-CROPSIM Wheat model: Temperature responses. In Alderman PD, Quilligan E, Asseng S, Ewert F, and Reynolds MP (Eds), Proceedings of the Workshop on Modeling Wheat Response to High Temperature. CIMMYT, El Batán, Mexico, 19-21 June 2013. Mexico, D.F.: CIMMYT.

Jagadish SVK, Muthurajan R, Oane R, et al. (2010) Physiological and proteomic approaches to address heat tolerance during anthesis in rice (Oryza sativa L). J Exp Bot 61, 143-156. DOI: 10.1093/jxb/erp289.

Jones JW, Hoogenboom G. Porter CH, et al. (2003) The DSSAT cropping system model. Europ J Agronomy 18:235-265.

Ju H, Lin E, Wheeler T, Challinor A, Jiang S (2013) Climate change modelling and its roles to Chinese crops yield. J Integr Agr 12:892-902. DOI:10.1016/S2095-3119(13)60307-X.

Kawase H, Yoshikane T, Hara M, et al. (2009) Intermodel variability of future changes in the Baiurainband estimated by the pseudo global warming downscaling method. J Geophys Res 114 (D24). DOI: 10.1029/2009JD011803.

Lauer A, Zhang C, Elison-Timm O (2013) Downscaling of climate change in the Hawaii region using CMIP5 results: On the choice of the forcing fields. J Climate 26: 10006-10030. DOI: http://dx.doi.org/10.1175/JCLI-D-13-00126.1.

Liu and Tao (2013) Probabilistic change of wheat productivity and water use in China for global mean temperature changes of $1^{\circ}, 2^{\circ}$, and $3^{\circ} \mathrm{C}$. Journal of Applied Meteorology and Climatology, 52, 114-129. DOI: 10.1175/JAMC-D-12-039.1.

Lobell DB, Asner GP (2003) Climate and management contributions to recent trends in US agricultural yields. Science, 299, 1032. DOI: 10.1126/science.1078475.

Long S P, Ainsworth E A, Rogers A, Ort D R (2004). Rising atmospheric carbon dioxide: plants FACE the future. Annu Rev Plant Biol. 55, 591-628. DOI: 10.1146/annurev.arplant.55.031903.141610.

Maurer E P, Hidalgo H G (2008) Utility of daily vs. monthly large-scale climate data: an inter-comparison of two statistical downscaling methods. Hydrol. Earth Syst. Sci. 12, 551-563. DOI: $10.5194 /$ hess-12-551-2008. 
Version of the article accepted for publication in Climatic Change published by Springer online 12 Jan 2017. Published

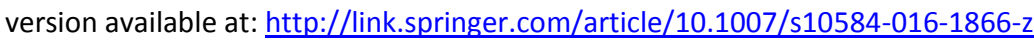

Accepted version downloaded from SOAS Research Online: https://eprints.soas.ac.uk/23476/

537

Moss RH, Edmonds JA, Hibbard KA, et al. (2010) The next generation of scenarios for climate change research and assessment. Nature 463:747-756. DOI: 10.1038/nature08823.

Palosuo T, Kersebaum KC, Angulo C, et al (2011) Simulation of winter wheat yield and its variability in different climates of Europe: a comparison of eight crop growth models. Eur J Agron 35:103-114. DOI:10.1016/j.eja.2011.05.001.

Pohlert T (2004) Use of empirical global radiation models for maize growth simulation. Agr Forest Meteorol 126:47-58. DOI:10.1016/j.agrformet.2004.05.003.

Porter J R, Gawith M (1999) Temperatures and the growth and development of wheat: a review, European Journal of Agronomy 10, 23-36. DOI: 10.1016/S1161-0301(98)00047-1.

Rasmussen R, Liu C, Ikeda K, et al. (2011) High-resolution coupled climate runoff simulations of seasonal snowfall over Colorado: a process study of current and warmer climate. J Climate 24:3015-3048. DOI:10.1175/2010JCLI3985.1.

Reich P B, Hobbie S E, Lee T D (2014) Plant growth enhancement by elevated $\mathrm{CO}_{2}$ eliminated by joint water and nitrogen limitation. Nature Geoscience 7, 920-924. DOI: 10.1038/ngeo2284.

Russell G, Wilson G W (1994) An Agri-Pedo-Climatological Knowledge-base of Wheat in Europe. Joint Research Centre, European Commission, Luxembourg, CL-NA-15789-EN-C, pp. 158.

Schär C, Frei C, Lüthi D, Davies H C (1996) Surrogate climate-change scenarios for regional climate models. Geophys Res Lett 23:669-672. DOI: 10.1029/96GL00265.

Semenov MA, Porter JR (1995) Climatic variability and the modelling of crop yields. Agr Forest Meteorol 73:265-283. DOI: 10.1016/0168-1923(94)05078-K.

Smith N G, Dukes J S (2013) Plant respiration and photosynthesis in global-scale models: incorporating acclimation to temperature and $\mathrm{CO}_{2}$. Global Change Biology 19, 45-63. DOI: 10.1111/j.1365-2486.2012.02797.x.

Tao F, Zhang Z (2013) Climate Change, wheat productivity and water use in the North China Plain: A new super ensemble-based probabilistic projection. Agr Forest Meteorol 170: 146-165. DOI:10.1016/j.agrformet.2011.10.003.

Teixeira EI, Fischer G, van Velthuizen H, Walter C, Ewert F (2013) Global hot-spots of heat stress on agricultural crops due to climate change. Agr Forest Meteorol 170:206-215.

DOI:10.1007/s10584-006-9051-4. 
Version of the article accepted for publication in Climatic Change published by Springer online 12 Jan 2017. Published version available at: $\underline{\text { http://link.springer.com/article/10.1007/s10584-016-1866-z }}$

Accepted version downloaded from SOAS Research Online: https://eprints.soas.ac.uk/23476/

Tian Z, Zhong H, Shi R, Sun L, Fischer G, Liang Z (2012) Estimating potential yield of wheat production in China based on cross-scale data-model fusion. Front Earth Sci 6:364-372. DOI:10.1007/s11707-012-0332-0.

Timsina J, Humphreys E (2006) Performance of CERES-Rice and CERES-Wheat models in rice-wheat systems: A review. Agricultural Systems, 90(1): 5-31. DOI:10.1016/j.agsy.2005.11.007.

Trnka M, Rötter RP, Ruiz-Ramos M, et al. (2014) Adverse weather conditions for European wheat production will become more frequent with climate change. Nature Climate Change 4:637-643. DOI:10.1038/NCLIMATE2242.

Tubiello, FN, Donatelli M, Rosenzweig C, and Stockle CO (2000) Effects of climate change and elevated CO2 on cropping systems: Model predictions at two Italian locations. Eur. J. Agron. 12:179-189.

USDA (2006) Wheat Situation and Outlook Yearbook. WHS-2006. Available at http://ers.usda.gov. USDA (2016) World Agricultural Production. Circular Series WAP 7-16. Available at http://usda.mannlib.cornell.edu/usda/current/worldag-production/worldag-production-07-12-2016. pdf.

van Vuuren DP, Edmonds J, Kainuma M, et al. (2011) The representative concentration pathways: an overview. Climatic Change, 109:5-31. DOI:10.1007/s10584-011-0148-z.

Váry Z, Mullins E, McElwain JC, Doohan FC (2015) The severity of wheat diseases increases when plants and pathogens are acclimatized to elevated carbon dioxide. Global Change Biology. Early online. DOI: $10.1111 / \mathrm{gcb} .12899$.

Xiong W, Conway D, Holman I, Lin E (2008) Evaluation of CERES-Wheat simulation of wheat production in China. Agron J 100:1720-1728. DOI:10.2134/agronj2008.0081.

Xiong W, Holman I, Lin E, et al. (2010) Climate change, water availability and future cereal production in China. Agr Ecosyst Environ 135:58-69. DOI:10.1016/j.agee.2009.08.015.

Yadav SS, Redden R, Hatfield JL, Lotze-Campen H, Hall AJ (2011) Crop Adaptation to Climate Change. John Wiley \& Sons, Inc.

Yoshikane T, Kimura F, Kawase H, Nozawa T (2012) Verification of the Performance of the Pseudo-Global-Warming Method for Future Climate Changes during June in East Asia. SOLA 
Version of the article accepted for publication in Climatic Change published by Springer online 12 Jan 2017. Published version available at: $\underline{\text { http://link.springer.com/article/10.1007/s10584-016-1866-z }}$

Accepted version downloaded from SOAS Research Online: https://eprints.soas.ac.uk/23476/

595 8:133-136. DOI:10.2151/sola.2012-033.

596 You L, Rosegrant MW, Wood S, Sun D (2009) Impact of growing season temperature on wheat

597 productivity in China. Agr Forest Meteorol, 149, 1009-1014. DOI:

$598 \quad$ http://dx.doi.org/10.1016/j.agrformet.2008.12.004.

599

600 
Version of the article accepted for publication in Climatic Change published by Springer online 12 Jan 2017. Published version available at: $\underline{\text { http://link.springer.com/article/10.1007/s10584-016-1866-z }}$

Accepted version downloaded from SOAS Research Online: https://eprints.soas.ac.uk/23476/

Table 1. Changes in the frequency of heat stress relative to the baseline (in days/decade)

\begin{tabular}{|c|c|c|c|c|c|c|}
\hline \multirow[b]{2}{*}{ Station } & \multicolumn{2}{|c|}{$2016-2025$} & \multicolumn{2}{|c|}{$2045-2055$} & \multicolumn{2}{|c|}{$2091-2100$} \\
\hline & Pre-anthesis & Grain-filling & Pre-anthesis & Grain-filling & Pre-anthesis & Grain-filling \\
\hline \multicolumn{7}{|c|}{ Winter wheat station } \\
\hline Tacheng (TC) & 21.8 & 11.4 & 28.8 & 20.4 & 40.6 & 35.4 \\
\hline Ruoqiang (RQ) & 70.7 & 63.7 & 85.4 & 82 & 102.9 & 102.1 \\
\hline Tongzhou (TZ) & 4.3 & 5.8 & 8.0 & 10.3 & 15.5 & 19.4 \\
\hline Linfen (LF) & 14.5 & 6.1 & 20.1 & 11.4 & 29.8 & 21.8 \\
\hline Taigu (TG) & 8.2 & 4.3 & 14.1 & 9.5 & 24.5 & 20.7 \\
\hline Jinghai (JH) & 4.9 & 2.1 & 8.7 & 4.6 & 16.7 & 10.9 \\
\hline Tai-an (TA) & 2.3 & 0.5 & 4.1 & 1.5 & 8.6 & 5.3 \\
\hline Dingxian (DN) & 7.6 & 8.5 & 12.8 & 14.9 & 21.4 & 26.8 \\
\hline Linyi (LY) & 7.2 & 4.5 & 12.6 & 7.1 & 20.6 & 10.3 \\
\hline Wugong (WG) & 12.4 & 8.9 & 16.1 & 12.3 & 22.1 & 13.6 \\
\hline Xuzhou (XZ) & 4.6 & 1 & 6.8 & 2.6 & 11.5 & 6.7 \\
\hline Tianshui (TS) & 17 & 2.4 & 23.9 & 5 & 34.4 & 12.9 \\
\hline Lasa (LS) & 0.8 & 0.1 & 2.5 & 0.5 & 10.3 & 0.8 \\
\hline Zhumadian (ZM) & 4.0 & 4.2 & 6.1 & 5.8 & 10.7 & 11.2 \\
\hline Kashi (KS) & 12.2 & 5.4 & 21.5 & 13.6 & 37 & 29.7 \\
\hline Nangong (NG) & 11.5 & 9.4 & 17.5 & 12.8 & 29.1 & 18.2 \\
\hline Zhengzhou (ZZ) & 10.8 & 3.1 & 15.5 & 4.3 & 18.8 & 9.2 \\
\hline Pu-an (PA) & 6.9 & 3.6 & 11 & 6.1 & 17.9 & 15.5 \\
\hline Hefei (HF) & 2.4 & 2.8 & 4.2 & 5.3 & 8.5 & 8.9 \\
\hline Kunming (KM) & 0.5 & 0.1 & 1.0 & 0.1 & 3.1 & 1.0 \\
\hline Baoshan (BS) & 0.2 & 0.1 & 0.3 & 0.1 & 0.5 & 0.4 \\
\hline Wenjiang (WJ) & 0.5 & 0.7 & 1.1 & 1.2 & 3.4 & 3.5 \\
\hline Songjiang (SJ) & 0.1 & 0.2 & 0.6 & 1 & 1.8 & 2.8 \\
\hline Macheng (MC) & 1.5 & 2.1 & 3.4 & 3.7 & 7.6 & 8.7 \\
\hline Jiangjin (JJ) & 0.3 & 1.7 & 0.7 & 2.8 & 2.4 & 6.1 \\
\hline Longhai (LH) & 0.2 & 0.1 & 0.3 & 0.1 & 0.5 & 0.1 \\
\hline \multicolumn{7}{|c|}{ Spring wheat station } \\
\hline Jiuquan (JQ) & 30.8 & 7.0 & 36 & 13.9 & 49.3 & 24.4 \\
\hline Tulufan (TL) & 91.7 & 105.1 & 107 & 122.3 & 120.8 & 136.2 \\
\hline Dunhuang (DH) & 56.1 & 46.9 & 73.5 & 70.5 & 92.3 & 92.4 \\
\hline Dingxi (DX) & 0.4 & 0.1 & 1.2 & 0.6 & 8.3 & 5.2 \\
\hline Guyuan (GN) & 1.4 & 0.0 & 4.6 & 0.6 & 12.9 & 6.7 \\
\hline $\begin{array}{c}\text { Huangyuan } \\
\text { (HY) }\end{array}$ & 0.2 & 2.1 & 1.4 & 4.6 & 8.5 & 9.7 \\
\hline Guyang (GY) & 74.6 & 29.2 & 93.5 & 42 & 114.8 & 63.6 \\
\hline Aletai (AL) & 43.6 & 7.7 & 58.5 & 16.2 & 72.5 & 28.4 \\
\hline Zhangbei (ZB) & 6.7 & 1.4 & 12.8 & 3.5 & 24.4 & 9.2 \\
\hline Huma (HM) & 27.7 & 18.7 & 39.6 & 26.6 & 55.2 & 40.4 \\
\hline
\end{tabular}

Note: Specific to this research, pre-anthesis period spans from the $20^{\text {th }}$ day before anthesis to the anthesis day, 
Version of the article accepted for publication in Climatic Change published by Springer online 12 Jan 2017. Published version available at: http://link.springer.com/article/10.1007/s10584-016-1866-z

Accepted version downloaded from SOAS Research Online: https://eprints.soas.ac.uk/23476/

606

Table 2. Ensemble mean yield changes, probability of yield loss, and standard deviation (S.D.)

607 of yield change relative to the baseline and under irrigated condition

\begin{tabular}{|c|c|c|c|c|c|c|}
\hline & \multicolumn{2}{|c|}{$2016-2025$} & \multicolumn{2}{|c|}{$2045-2055$} & \multicolumn{2}{|c|}{$2091-2100$} \\
\hline Station & $\begin{array}{l}\text { Mean yield } \\
\text { change in \% } \\
\text { (Probability } \\
\text { in } \% \text { ) }\end{array}$ & $\begin{array}{l}\text { S.D. in } \mathrm{kg} / \mathrm{ha} \\
\text { (as \% of } \\
\text { baseline } \\
\text { yield) }\end{array}$ & $\begin{array}{l}\text { Mean yield } \\
\text { change in \% } \\
\text { (Probability } \\
\text { in } \% \text { ) }\end{array}$ & $\begin{array}{l}\text { S.D. in } \mathrm{kg} / \mathrm{ha} \\
\text { (as \% of } \\
\text { baseline } \\
\text { yield) }\end{array}$ & $\begin{array}{l}\text { Mean yield } \\
\text { change in \% } \\
\text { (Probability } \\
\text { in } \% \text { ) }\end{array}$ & $\begin{array}{l}\text { S.D. in } \mathrm{kg} / \mathrm{ha} \\
\text { (as \% of } \\
\text { baseline } \\
\text { yield) }\end{array}$ \\
\hline \multicolumn{7}{|c|}{ Winter wheat station } \\
\hline Tacheng & $-7.4(80.6)$ & $447.3(7.7)$ & $-8.2(80.6)$ & $484.6(8.4)$ & $-7.9(74.6)$ & $627.9(10.9)$ \\
\hline Ruoqiang & $-3.6(94.0)$ & $144.0(2.6)$ & $-3.2(94.0)$ & $231.5(4.2)$ & $-5.1(91.0)$ & $379.9(7.0)$ \\
\hline Tongzhou & $-2.8(71.6)$ & $424.1(6.1)$ & $-5.8(58.2)$ & $441.6(6.3)$ & $-8.3(70.1)$ & $581.2(8.3)$ \\
\hline Linfen & $-2.8(68.7)$ & $302.0(5.2)$ & $-5.6(85.1)$ & $302.1(5.2)$ & $-9.2(92.5)$ & $426.5(7.4)$ \\
\hline Taigu & $-6.5(86.6)$ & $325.5(5.5)$ & $-2.2(61.2)$ & $321.4(5.4)$ & $-3.1(68.7)$ & $337.7(5.7)$ \\
\hline Jinghai & $-6.0(88.1)$ & $280.3(5.2)$ & $-3.5(73.1)$ & $278.1(5.2)$ & $-5.5(76.1)$ & $404.3(7.6)$ \\
\hline Taian & $-4.0(88.1)$ & $218.7(3.4)$ & $-3.1(82.1)$ & $234.7(3.6)$ & $-5.2(82.1)$ & $375.6(5.8)$ \\
\hline Dingxian & $-8.9(82.1)$ & $349.4(8.9)$ & $-12.4(92.5)$ & $437.5(11.1)$ & $-16.2(83.6)$ & $610.1(15.5)$ \\
\hline Linyi & $-3.0(67.2)$ & $509.4(10.1)$ & $8.2(70.9)$ & $500.8(9.9)$ & $13.6(80.4)$ & $568.6(11.3)$ \\
\hline Wugong & $-3.7(61.9)$ & $330.0(6.9)$ & $-7.9(69.2)$ & $315.5(6.6)$ & $-10.8(71.4)$ & $501.7(10.5)$ \\
\hline Xuzhou & $-6.2(94.0)$ & $274.4(3.8)$ & $-7.6(91.0)$ & $333.4(4.6)$ & $-8.2(91.0)$ & $494.7(6.8)$ \\
\hline Tianshui & $-10.7(92.5)$ & $384.8(7.8)$ & $-12.1(91.0)$ & $514.5(10.4)$ & $-15.0(85.1)$ & $638.9(12.9)$ \\
\hline Lasa & $-8.3(100.0)$ & $359.3(3.7)$ & $-7.6(94.0)$ & $466.3(4.7)$ & $-9.2(97.0)$ & $557.6(5.7)$ \\
\hline Zhumadian & $-3.8(88.1)$ & $283.4(6.0)$ & $-4.9(88.1)$ & $412.2(8.8)$ & $-8.5(80.6)$ & $429.9(9.1)$ \\
\hline Kashi & $-5.4(85.1)$ & $415.3(6.9)$ & $-6.3(88.1)$ & $369.5(6.2)$ & $-9.4(97.0)$ & $414.4(6.9)$ \\
\hline Nangong & $-5.8(78.1)$ & $210.4(4.0)$ & $-7.5(83.3)$ & $245.7(4.7)$ & $-9.6(95.2)$ & $381.2(7.2)$ \\
\hline Zhengzhou & $-4.7(70.5)$ & $255.6(4.9)$ & $-7.5(77.8)$ & $273.6(5.3)$ & $-9.2(82.4)$ & $501.7(9.6)$ \\
\hline Puan & $-1.9(58.2)$ & $335.1(7.5)$ & $-1.9(56.7)$ & $302.7(6.8)$ & $-4.3(68.7)$ & $372.6(8.3)$ \\
\hline Hefei & $-0.7(58.2)$ & $524.2(7.1)$ & $-2.1(69.9)$ & $414.9(5.7)$ & $-6.1(70.3)$ & $603.7(8.2)$ \\
\hline Kunming & $-4.6(80.6)$ & $426.7(5.4)$ & $-5.0(83.6)$ & $387.3(4.9)$ & $-4.2(77.6)$ & $541.1(6.8)$ \\
\hline Baoshan & $-1.5(53.7)$ & $302.9(4.6)$ & $-4.7(89.6)$ & $255.8(3.9)$ & $-7.2(88.1)$ & $432.4(6.6)$ \\
\hline Wenjiang & $-3.7(80.6)$ & $471.3(7.0)$ & $-4.3(80.6)$ & $459.8(6.9)$ & $-5.8(65.7)$ & $549.7(8.2)$ \\
\hline Songjiang & $-3.1(85.1)$ & $310.5(7.1)$ & $-4.9(79.1)$ & $256.9(5.9)$ & $-5.2(68.7)$ & $387.3(8.9)$ \\
\hline Macheng & $-3.4(94.0)$ & $313.5(5.1)$ & $-7.0(91.0)$ & $388.9(6.3)$ & $-9.8(79.1)$ & $499.4(8.1)$ \\
\hline Jiangjin & $-5.6(62.7)$ & $586.0(18.1)$ & $-7.6(34.3)$ & $642.8(19.8)$ & $-10.9(32.8)$ & $851.3(26.3)$ \\
\hline Longhai & $-3.1(68.7)$ & $306.8(11.4)$ & $-4.2(67.2)$ & $342.2(12.7)$ & $-4.9(56.7)$ & $529.9(19.7)$ \\
\hline \multicolumn{7}{|c|}{ Spring wheat station } \\
\hline Jiuquan & $-9.1(92.5)$ & $269.1(5.4)$ & $-15.3(95.2)$ & $452.9(15.9)$ & $-19.5(98.4)$ & $843.6(29.6)$ \\
\hline Tulufan & $-12.4(92.5)$ & $201.3(8.9)$ & $-23.3(98.5)$ & $273.2(12.0)$ & $-33.6(98.5)$ & $489.9(21.6)$ \\
\hline Dunhuang & $-5.4(89.6)$ & $209.7(4.9)$ & $-10.7(98.5)$ & $339.0(8.0)$ & $-15.2(94.0)$ & $572.1(13.5)$ \\
\hline Dingxi & $-3.1(79.1)$ & $86.7(3.6)$ & $-4.8(83.6)$ & $105.3(4.4)$ & $-7.4(88.1)$ & $174.2(7.2)$ \\
\hline Guyuan & $-4.1(89.6)$ & $116.6(4.1)$ & $-6.6(98.5)$ & $114.9(4.0)$ & $-9.3(95.5)$ & $186.7(6.5)$ \\
\hline Huangyuan & $-6.0(95.5)$ & $193.2(3.4)$ & $-9.4(100.0)$ & $254.0(4.5)$ & $-12.0(98.5)$ & $397.5(7.0)$ \\
\hline Guyang & $-12.5(100.0)$ & $62.6(3.8)$ & $-18.5(100.0)$ & $109.5(6.6)$ & $-24.2(100.0)$ & $236.1(14.3)$ \\
\hline Aletai & $-10.7(95.2)$ & $321.7(8.2)$ & $-19.2(96.7)$ & $484.1(12.4)$ & $-25.6(98.4)$ & $745.2(19.1)$ \\
\hline Zhangbei & $-8.9(100.0)$ & $175.1(4.1)$ & $-9.1(97.0)$ & $199.2(4.7)$ & $-12.9(97.0)$ & $386.3(9.0)$ \\
\hline Huma & $-9.9(98.5)$ & $121.4(5.4)$ & $-11.1(97.0)$ & $133.9(6.0)$ & $-15.7(95.5)$ & $249.9(11.2)$ \\
\hline
\end{tabular}



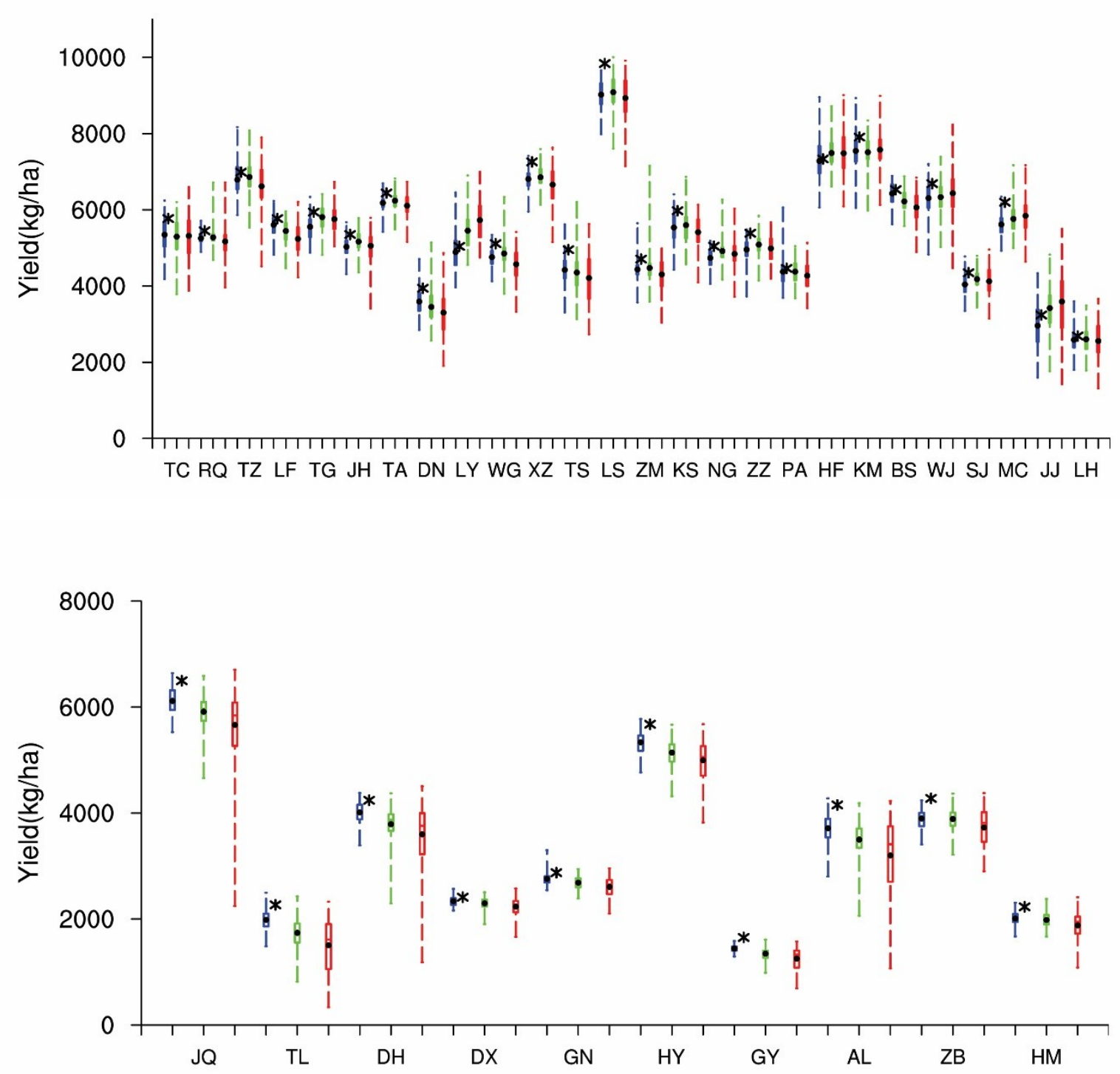

612 Fig.1 The ensemble yields of irrigated winter wheat (upper panel) and spring wheat (lower 613 panel) in early (blue), middle (green), and the end (red) of the 21 st century. The asterisk 614 represents the 10-year average irrigated wheat yield from 1996 to 2005 simulated with the 615 observation data as the baseline. The dot denotes the ensemble mean. 